\title{
GAMMA-TOCOTRIENOL DOES NOT COMPETE WITH MITOXANTRONE TO BE EFFLUXED FROM ABCG2 OVEREXPRESSING CELLS
}

\author{
KARL VERN TAN*; SANDY HWEI SAN LOH**; DEBORAH BRIGGS; \\ IAN KERR ${ }^{\ddagger}$ and SUE-MIAN THEN* ${ }^{*}$
}

\begin{abstract}
The human adenosine triphosphate (ATP)-binding cassette ( $A B C$ ) subfamily G2 (ABCG2) half transporter of the G-subfamily that is involved in transportation of an extensive range of substrates, including xenobiotics and endogenous compounds. ABCG2 transporter upregulation in many cancerous tissues is often linked to multiple drug resistance (MDR) due to its involvement in efflux of various drugs. Gamma-tocotrienol ( $\gamma$ T3) is an isoform of vitamin $E$ that possesses promising anti-cancer effects via various mechanisms, however, transportation of $\gamma \mathrm{T} 3$ remains unknown and its therapeutic effects might be limited by MDR. This project, thus, sought to study the anti-cancer effect (i.e. anti-proliferative effect) of $\gamma \mathrm{T} 3$ in an ABCG2-expressing breast cancer cell line [Michigan Cancer Foundation-7-mitoxantrone (MCF7-MX)] and the possibility of $\gamma \mathrm{T} 3$ to be transported via ABCG2 transporter. It was demonstrated that after $72 \mathrm{hr}$ treatment with $\gamma \mathrm{T} 3$, cell proliferation of MCF7-MX cells was inhibited with $I_{50}=43 \mu M$. The co-administration of $\gamma \mathrm{T} 3$ with $M X, a$ substrate of ABCG2, has shown that $\gamma T 3$ is not a competitor for MX transport ( $p>0.05)$. The data confirms the anti-proliferative role of $\gamma \mathrm{T} 3$ in ABCG2 expressing cells and suggests that ABCG2 might have a minimal role in $\gamma \mathrm{T} 3$ transport. This result provides an essential basis for the further study of $\gamma \mathrm{T} 3$ as an anti-cancer compound.
\end{abstract}

Keywords: gamma tocotrienol, ABCG2 transporter, multidrug resistance, mitoxantrone, vitamin E.

Received: 16 August 2019; Accepted: 13 February 2020; Published online: 14 September 2020.

\section{INTRODUCTION}

Gamma tocotrienol $(\gamma \mathrm{T} 3)$ is one of the eight natural forms of vitamin $\mathrm{E}$ that can be found abundantly in palm oil and rice bran oil (Aggarwal et al., 2010; Ahsan et al., 2014). The $\gamma \mathrm{T} 3$ could be beneficial against various cancers via numerous mechanisms namely anti-proliferative, apoptosis induction, immunomodulatory function aside its well-known antioxidant activity (Ahsan et al., 2014). It is notable that $\gamma \mathrm{T} 3$ has multiple molecular targets that are

\footnotetext{
* Division of Biomedical Sciences,

Faculty of Science and Engineering,

University of Nottingham Malaysia,

43500 Semenyih, Selangor, Malaysia.

E-mail: then.sue-mian@nottingham.edu.my

** School of Bioscience, Faculty of Science and Engineering, University of Nottingham Malaysia,

43500 Semenyih, Selangor, Malaysia.

‡ School of Life Sciences, University of Nottingham,

Queen's Medical Centre,

Nottingham, United Kingdom.
}

involved in transcription, translation and posttranslational protein levels and may interact directly with cellular targets to mediate its anti-cancer effects via various signalling pathways (Aggarwal et al., 2010).

The effectiveness of $\gamma \mathrm{T} 3$ as an anti-cancer agent will be highly dependent on its availability for cancer cells. However, cancer cells often overexpress multiple drug resistance (MDR) transporters, such as ABCG2 [adenosine triphosphate (ATP)-binding cassette (ABC) subfamily G2]. ABCG2, also known as breast cancer resistance protein (BRCP), is a 655-amino acid polypeptide chain with a molecular weight of $70 \mathrm{kDa}$ (Doyle et al., 1998). ABCG2 is expressed naturally in various tissues and organs to protect the body from toxicity associated with xenobiotic exposure; however, when expressed on the surface of cancer cells, this protective mechanism often leads to MDR, thus leads to chemotherapy failure due its efflux activity (Nakanishi and Ross, 2012; Mo and Zhang, 2012; Stacy et al., 2013; Horsey 
et al., 2016). For example, ABCG2 has been found to be frequently expressed in hematopoietic malignancies including acute myelogenous leukaemia (AML) and acute lymphoblastic leukaemia (ALL) which lead to poorer disease-free survival rate and lower response rate (Benderra et al., 2004; Uggla et al., 2005; Stacy et al., 2013).

ABCG2 has been shown to transport a broad range of substrates such as chemotherapeutic drugs, hydrophobic or lipophilic substances (Mo and Zhang, 2012). As ABCG2 also transports sulphate and glucuronide conjugates (Suzuki et al., 2003; Imai et al., 2003), it is possible that ABCG2 is involved in excretion of vitamin $\mathrm{E}$ since it was proposed that vitamin E metabolite, carboxyethyl-hydroxychromanols (CEHC) needs to be sulphonated or glucuronidated to be excreted via transporters (Pope et al., 2000; Kiyose et al., 2001).

To our knowledge, there is no reported study on tocotrienol (T3) as substrates of ABCG2. As ABCG2 substrates overlap to some extent with $A B C$ subfamily B member 1 (ABCB1) P-glycoprotein 1 (P-gp), studies done on the interaction between ABCB1 and other vitamin E isoforms may well serve as a guideline. Excess $\gamma \mathrm{T} 3$ has been shown to upregulate activity and expression of ABCB1 messenger ribonucleic acid (mRNA) and protein (Zhou et al., 2004; Abuznait et al., 2011). Zhou et al. (2004) showed that all T3 $\left(\alpha-, \beta-, \gamma_{-}, \delta\right.$-) activate the nuclear receptor, pregnane $X$ receptor (PXR) that mediates expression of various genes, including ABCG2, to regulate xenobiotic detoxification and drug clearance in the liver (Landes et al., 2003; Zhou et al., 2004). Collectively, this suggests that T3 is potentially involved in the upregulation of ABCG2 for efflux purposes to prevent toxicity.

Whilst $\gamma \mathrm{T} 3$ has the potential to be utilised as an anti-cancer agent, it is important to study its interaction with ABCG2 to identify any drug-drug interaction and to maximise the therapeutic value of $\gamma \mathrm{T}$, which often has low bioavailability. This study thus aims to investigate the potential involvement of ABCG2 in the cellular transport of $\gamma \mathrm{T} 3$.

\section{MATERIALS AND METHODS}

\section{Cell Culture and Reagents}

All tissue culture reagents were from SigmaAldrich, St Louis, Missouri, USA unless stated otherwise. The $\gamma \mathrm{T} 3$ was a gift from Davos Life Science (Singapore) which was a pure compound extracted from palm oil and dissolved in ethanol. The breast cancer cell line MCF7 (ATCC) and MCF7MX (ATCC) cells that were developed previously (Nakagawa et al., 1992) were grown in Dulbecco's Modified Eagle Medium (DMEM, + $4.5 \mathrm{~g} \mathrm{litre}^{-1}$ D-glucose, $0.11 \mathrm{~g}$ litre $^{-1}$ sodium pyruvate and $0.56 \mathrm{~g}$ litre $^{-1}$ L-glutamine) supplemented with $10 \%(\mathrm{v} / \mathrm{v})$ fetal calf serum (FCS) and 100 units $/ \mathrm{ml}$ penicillin and $100 \mu \mathrm{g} \mathrm{ml}^{-1}$ streptomycin at $37^{\circ} \mathrm{C}, 5 \%$ carbon dioxide $\left(\mathrm{CO}_{2}\right)$. Cells were passaged at $80 \%$ confluence by trypsinisation. The detached cells were removed from the flask in $5 \mathrm{ml}$ medium and centrifuged at $1300 \mathrm{~g}$ for $5 \mathrm{~min}$. The pellets were re-suspended in medium and passaged in 1:5 ratio into new flasks. Where necessary, cell density was determined using a haemocytometer.

\section{Cell Proliferation Assay}

The cells were seeded at cell density of $1.2 \times 10^{4}$ cells/well in $100 \mu \mathrm{l}$ medium and left to attach for $24 \mathrm{hr}$ at $37^{\circ} \mathrm{C}, 5 \% \mathrm{CO}_{2}$. Then, media were changed to fresh media containing $1 \%$ FCS in the presence of $0-100 \mu \mathrm{M} \gamma \mathrm{T} 3$ followed by $72 \mathrm{hr}$ incubation in dark, at $37^{\circ} \mathrm{C}, 5 \% \mathrm{CO}_{2}$. Prior to cell treatment, the $\gamma \mathrm{T} 3$ stock solution was diluted with equal amount of $100 \%$ FCS and incubated in dark for $16 \mathrm{hr}$, followed by serial dilution with 1:1 mixture of $100 \%$ ethanol and $1 \%$ FCS media, the final concentration of ethanol in the cell culture was $<0.05 \%$. The cell proliferation was then determined with CellTiter $96^{\circledR}$ Aqueous One Solution Cell Proliferation Assay (Promega, Fitchburg, Wisconsin, USA) which uses the colorimetric reagent 3-(4,5-dimethylthiazol-2-yl)-5(3-carboxymethoxyphenol)-2-(4-sulphophenyl)-2 $\mathrm{H}$ tetrazolium (MTS) and the electron coupling agent phenazine methosulphate (PMS) according to the manufacturer's instruction. Briefly, $20 \mu$ of CellTiter $966^{\circledR}$ reagent was added to each well and incubated at $37^{\circ} \mathrm{C}$ in $5 \% \mathrm{CO}_{2}$ for $2 \mathrm{hr}$. The colour intensity, which is proportional to the number of metabolically active cells, was determined at $450 \mathrm{~nm}$ with Multiskan FC microplate photometer (Thermo Fisher Scientific, Waltham, Massachusetts, USA).

\section{Protein Detection Using SDS-PAGE and Western Blot}

Cells were harvested as described (Haider et al., 2011). The protein concentrations were determined using a modified Lowry assay method (Lowry et al., 1951) using reagents from detergent compatible (DC) protein assay kit (Bio-Rad, Hercules, California, USA) according to manufacturer's instruction with bovine serum albumin (BSA) as a standard. The cell lysates (10 $\mu \mathrm{g}$ of protein) were resolved by sodium dodecyl sulphate-polyacrylamide gel electrophoresis (SDSPAGE) (10\%). Following transfer on nitrocellulose membrane, the membrane was blocked using 5\% non-fat milk in PBST (PBS with $0.1 \%$ (v/v) Tween 20, (Thermo Fisher Scientific, Waltham, Massachusetts, USA) for $1 \mathrm{hr}$ at room temperature. ABCG2 was then bound using primary monoclonal mouse antibody BXP-21 (1:1000 dilution) at $4^{\circ} \mathrm{C}$, overnight, followed by secondary antibody, polyclonal rabbit 
anti-mouse IgG antibody conjugated with horse radish peroxidase (HRP) (1:2000) for $1 \mathrm{hr}$ at room temperature. Chemiluminescence was detected using SuperSignal West Pico Chemiluminescent Substrate (Thermo Fisher Scientific, Waltham, Massachusetts, USA).

\section{Accumulation Assay}

Both MCF7 and MCF7-MX cells were seeded as described previously (Haider et al., 2015). The plates were incubated overnight at $37^{\circ} \mathrm{C}, 5 \%$ $\mathrm{CO}_{2}$ before the media was replaced in low light conditions with phenol red free media containing 8 $\mu \mathrm{M}$ mitoxantrone alone or with $8 \mu \mathrm{M}$ mitoxantrone combined with $500 \mathrm{nM}$ Ko143 or $8 \mu \mathrm{M}$ mitoxantrone with various concentration of $\gamma \mathrm{T} 3(3.13-100 \mu \mathrm{M})$ for an hour at $37^{\circ} \mathrm{C}, 5 \% \mathrm{CO}_{2}$. Following incubation, the cells were fixed as described previously (Haider et al., 2015). The accumulation of $M X$ in the cells were measured using SpectraMax M2 (Molecular Device, San Jose, California, USA) at excitation wavelength $\left(\lambda_{\mathrm{Ex}}\right)$ of $607 \mathrm{~nm}$ and emission wavelength $\left(\lambda_{\mathrm{Em}}\right)$ of $684 \mathrm{~nm}$. Fluorescence data were corrected for values obtained from incubation with the maximal final solvent concentration used $[1 \% \mathrm{v} / \mathrm{v}$ dimethyl sulphoxide (DMSO)].

\section{Cell Fixation and Mounting for Fluorescence Imaging}

Prior to cell seeding, the coverslips were sterilised in $70 \% \mathrm{v} / \mathrm{v}$ ethanol and coated with poly-L-lysine as described previously (Haider et al., 2015) in 12-well plates. Both MCF7 and MCF7-MX cells were seeded in a total volume of $1 \mathrm{mlDMEM}$ media and incubated overnight at $37^{\circ} \mathrm{C}, 5 \% \mathrm{CO}_{2}$. The cells were then fixed with $4 \%$ paraformaldehyde (PFA) as described above. Cells were incubated with an exogenous aminecontaining reagent, $50 \mathrm{mM} \mathrm{NH}_{4} \mathrm{Cl}$ in PBS for $15 \mathrm{~min}$ followed by incubation in blocking buffer $(0.5 \%$ $(\mathrm{w} / \mathrm{v}) \mathrm{BSA}$ in PBS) for another $15 \mathrm{~min}$. Coverslips were incubated in primary mouse monoclonal antiABCG2 antibody, clone 5D3 (Millipore, Burlington, Massachusetts, USA), diluted at 1:200 in blocking buffer for $30 \mathrm{~min}$. The coverslips were washed four times with blocking buffer and then with secondary Alexa-Fluor 647 goat anti-mouse monoclonal antibody (Life Technologies, Carlsbad, California, USA) diluted at 1:1000 in blocking buffer for another $30 \mathrm{~min}$. The cells were washed several times with blocking buffer and mounted onto microscope slides using FluoroGel (GeneTex, Irvine, California, USA). The slides were viewed using LSM710 confocal laser scanning microscope from Carl Zeiss Microscopy (Zeiss, Oberkochen, Germany). A 1024×1024 image at a 12 bit depth was captured with $647 \mathrm{~nm}$ laser at $2 \%$ using water-immersion objective C-Apochromat 40x NA $1.20^{\prime}$.

\section{Statistical Analysis}

All results presented in the article are expressed as mean and standard deviation $( \pm \mathrm{SD})$ from three experiments ( $\mathrm{n}=3$, each with six internalised repeats). Comparisons between groups were made using oneway analysis of variance (ANOVA) with Dunnett test or t-test as mentioned. The normality of distribution was tested using Shapiro-Wilk normality test. For cytotoxicity assay, the $\mathrm{IC}_{50}$ values were calculated using classical dose-response equation: $\mathrm{Y}=$ bottom + (top-bottom) $/\left[1+10^{\wedge}\left(\operatorname{LogIC}_{50}-X\right)^{\star}\right.$ hillslope $]$.

All statistical analyses were performed using GraphPad Prism 7.02, California, USA. A $p$ value of $<0.05$ was considered statistically significant.

\section{RESULTS}

For this study, a pair of cell lines with negative and positive ABCG2 expression, namely MCF7 and MCF7-MX cells were used. A range of experiments were carried out to analyse the expression of ABCG2 in the target cell lines, the effect of $\gamma \mathrm{T} 3$ on cell survival and on the ABCG2-mediated transport of MX.

The expression of ABCG2 at protein level was ascertained by immunoblotting with an ABCG2specific primary monoclonal antibody, BXP-21 (Figure 1). The western blot analysis exhibited a single immuno-reactive band at approximately $72 \mathrm{kDa}$, corresponding to the expected molecular mass of ABCG2 in all lanes loaded with MCF7MX cell lysates. However, no band was observed in lanes loaded with MCF7 cell lysates, even when western blots were exposed to photographic film for extended periods of time. This finding indicated that ABCG2 protein was expressed in MCF7-MX cells but was undetectable in MCF7 cells.

Immunolocalisation of ABCG2 protein in cells was performed on fixed MCF7 and MCF7-MX cells using 5D3 antibody that recognises an extracellular epitope of ABCG2 (Özvegy-Laczka et al., 2005) followed by secondary antibody conjugated to AlexaFluor 647. This enables visualisation of protein on the surface of intact cells. The immunofluorescence data as analysed by confocal microscope revealed that ABCG2 was localised on cell surface of MCF7-MX cells (Figure 2b) but not on MCF7 cells (Figure 2a).

These showed that ABCG2 was expressed and localised on plasma membrane of MCF7-MX cells but was not expressed or expressed below detectable levels in the parental MCF7 cells.

The cytotoxicity of $\gamma \mathrm{T} 3$ on both cell lines can be evaluated by determination of the $\mathrm{IC}_{50}$ values, which correspond to the concentration of $\gamma \mathrm{T} 3$ that are able to reduce $50 \%$ of cell viability. After $72 \mathrm{hr}$ treatment with $\gamma \mathrm{T} 3$, the $\log \mathrm{IC}_{50}$ values were $-4.66 \pm$ 
0.08 and $-4.36 \pm 0.04$ for MCF7 and MCF7-MX cells respectively. This corresponds to Mcf7-MX cells having an approximately two-fold resistance to $\gamma \mathrm{T} 3$ $(43 \mu \mathrm{M})$ compared to parental Mcf7 cells $(22 \mu \mathrm{M})$. Unpaired t-test analysis indicated that there was a significant difference $(\mathrm{p}<0.01)$ in the cytotoxicity of the cell lines to $\gamma \mathrm{T} 3$ during $72 \mathrm{hr}$ incubation.

Such differences in cytotoxicity prompted us to consider whether $\gamma \mathrm{T} 3$ was a transport substrate of ABCG2 and so we investigated the potency of $\gamma \mathrm{T} 3$ to compete with the ABCG2 mediated transport of a well characterised substrate MX. Figure $3 a$ confirmed that significant difference $(p<0.001)$ in intracellular MX accumulation between the negative control MCF7 cells and MCF7-MX cells

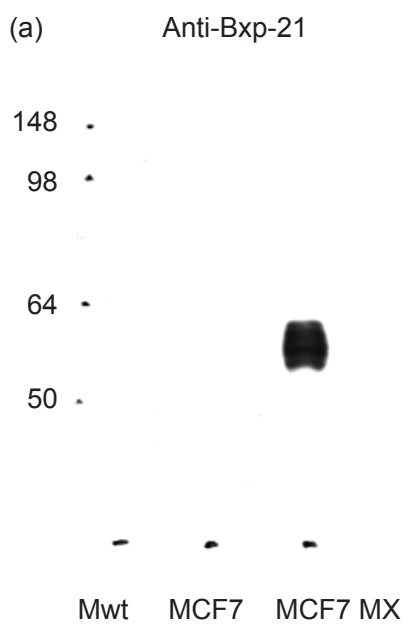

with overexpression of ABCG2, in which the latter had lower intracellular MX accumulation. This indicated that ABCG2 was involved in the efflux of MX from the cells. In addition, the administration of the ABCG2 inhibitor, Ko143 resulted in a significant increase in accumulation of MX by seven-fold (7.17 $\pm 2.3, \mathrm{p}<0.0001$ ) (Figure 3c, second column of data). In contrast, the negative control MCF7 cells showed no significant difference in MX accumulation in the presence and absence of ABCG2 inhibitor, Ko143 (Figure 3b). Any compound which inhibits MX transport (either by non-competitive inhibition, e.g. by inhibiting the transport mechanism of ABCG2, or by competing with MX for transport) will result in increased accumulation of MX.

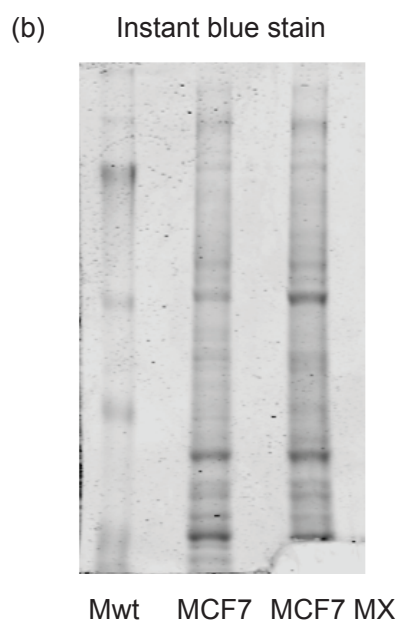

Figure 1. (a) Western blot analysis of ABCG2 [adenosine triphosphate (ATP)-binding cassette (ABC) subfamily G2] expression, and (b) total protein expression in MCF7-MX [Michigan Cancer Foundation-7-mitoxantrone] and MCF7 cells. ABCG2 with molecular weight of approximately 72 kDa was detected only in lanes loaded with MCF7-MX cell lysates but not in lanes loaded with MCF7 cell lysates as shown in (a) band smearing is due to glycosylation of ABCG2 and $(b)$ showed confirmed equal protein loading of cell lysates.

(a)

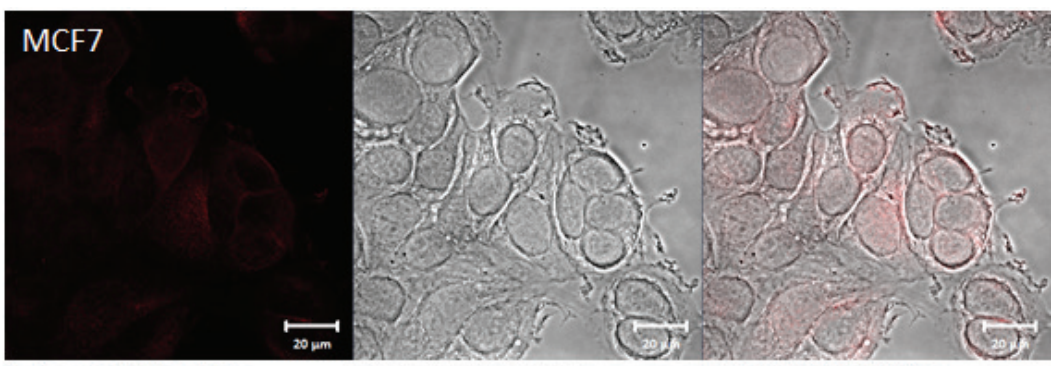

(b)

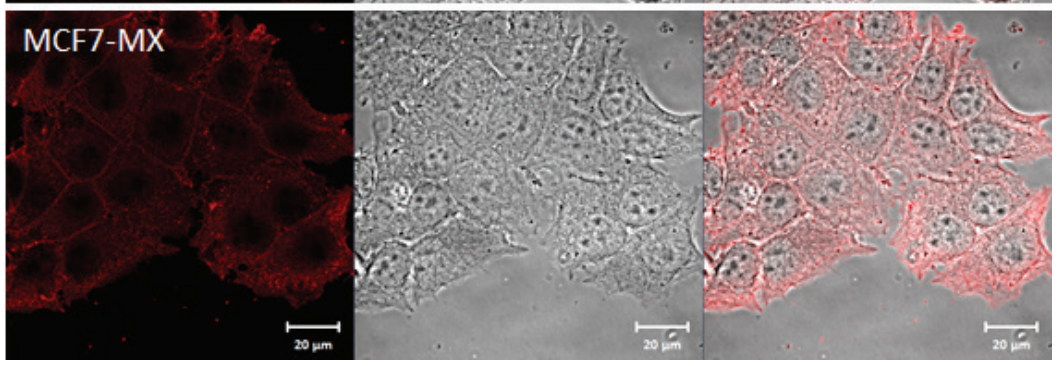

Note: Scale bar $=20 \mu \mathrm{m}$.

Figure 2. Confocal images of ABCG2 [adenosine triphosphate (ATP)-binding cassette (ABC) subfamily G2] expression. (a) MCF7 (Michigan Cancer Foundation-7), and (b) MCF7-MX (mitoxantrone) cells. 
To validate the possibility of $\gamma \mathrm{T} 3$ as a substrate of ABCG2, $\gamma \mathrm{T} 3$ was administered at various concentrations with MX and the accumulation of MX in the cells was measured. The results presented in Figure 3 as mean \pm standard deviation of three independent experiments, each with six internalised repeats. All data were normalised against DMSO only control. In both the parental MCF7 cells (Figure $3 b$ ) and the ABCG2-expressing MCF7-MX cells (Figure 3c), no significant difference in MX accumulation was observed with the addition of $\gamma \mathrm{T} 3$ to MX despites at its highest concentration $(100 \mu \mathrm{M})$ $(p>0.05)$. All the data obtained passed the ShapiroWilk normality test (alpha $=0.05$ ). (a)

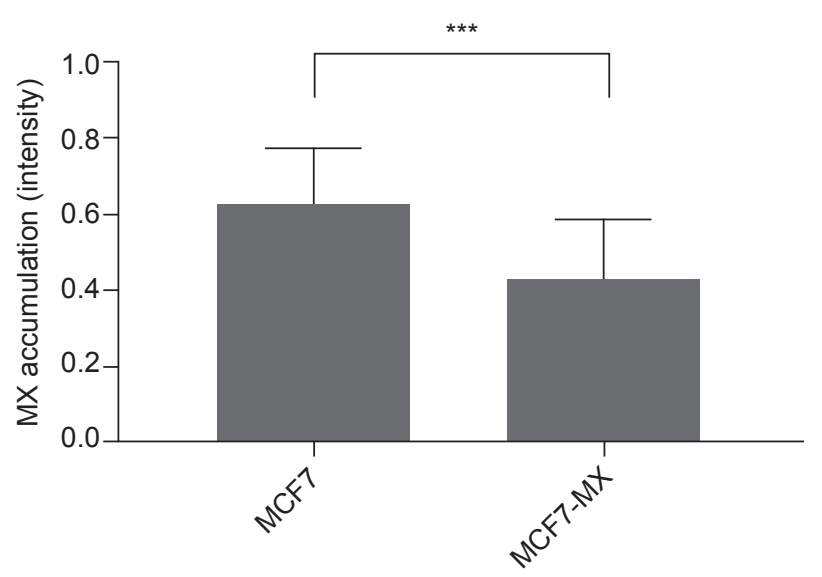

Cell line (b)

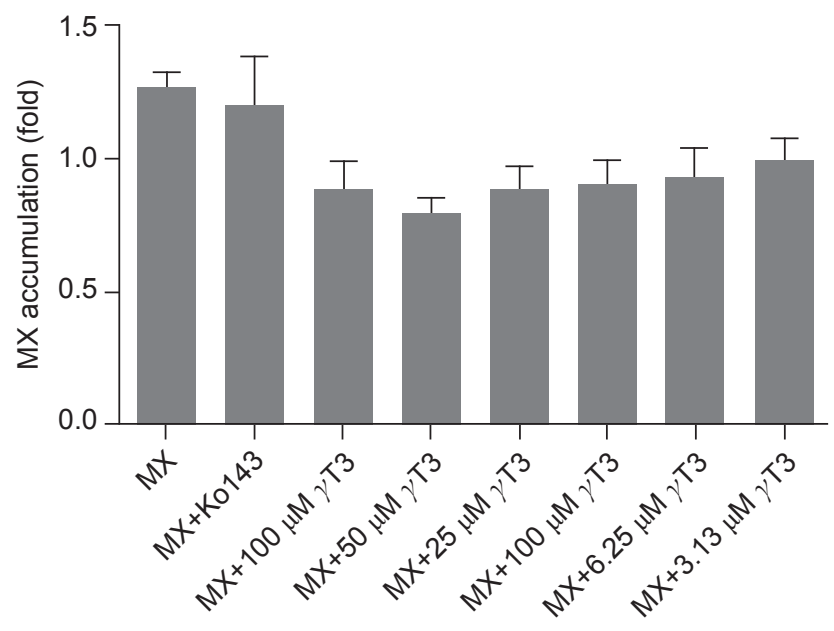

(c)

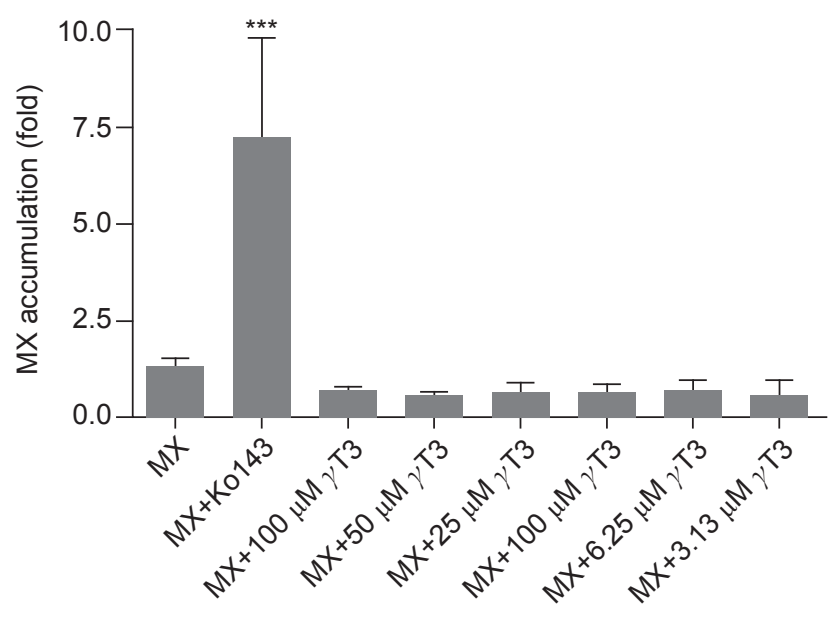

Note: ${ }^{* * *} \mathrm{p}<0.001$, t-test. ${ }^{* * * *} \mathrm{p}<0.0001$ compared to control (MX alone) as indicated by one-way analysis of variance (ANOVA) followed by Dunnett post-hoc test.

Figure 3. Gamma-tocotrienol does not inhibit mitoxantrone (MX) transport in both MCF7 (Michigan Cancer Foundation-7) and MCF7-MX cells. (a) MCF7 cells showed significant difference in the MX accumulation compared to MCF7-(MX) cells in normal condition with MCF7-MX had a lower MX accumulation. (b) MCF7 cells showed no significant difference in MX accumulation with the addition of inhibitor, Ko143 or with combination of $\gamma$ T3. (c) MCF7-MX cells showed a significant increase in MX accumulation by approximately seven-fold (7.17 \pm 2.3 ) with the presence of ABCG2 [adenosine triphosphate (ATP)-binding cassette (ABC) subfamily G2] inhibitor, Ko143. However, no significant difference was shown between cells treated with MX alone and cells treated with combination of MX and $\gamma T 3$ at various concentrations in both cell lines. Data presented as mean $\pm S D$, $n=3$ (each with six internalised repeats). 


\section{DISCUSSION}

Overexpression of ABCG2 in various cancer cell lines often results in MDR and leads to the failure of chemotherapy due to the efflux activity of the transporter (Scharenberg et al., 2002; Islam et al., 2005; Mo and Zhang, 2012). As $\gamma \mathrm{T} 3$ has been shown to display potent anti-cancer activity via various mechanisms (Shah et al., 2003; Sylvester et al., 2005; Kannappan et al., 2010), it was of interest to study the possibility of $\gamma \mathrm{T} 3$ being a transport substrate of ABCG2, which might limit its therapeutic value.

Studies confirmed that ABCG2 acts as an efflux pump to reduce intracellular drug accumulation (Ross et al., 1999; Miyake et al., 1999). Thus, it was of interest to determine whether ABCG2 localisation to the plasma membrane in the MX-resistant MCF7-MX cells corresponds to its function as drug efflux pump. Similar to previous studies (Ross et al., 1999; Austin Doyle and Ross, 2003), the ABCG2 is overexpressed in MCF7-MX cells and localised on plasma membrane (Figures 1 and $2 b$ ). Minimal fluorescent was detected intracellularly in MCF7-MX cells (Figure 2b), this might due to the endocytosis of ABCG2 upon 5D3 binding, where the internalised ABCG2 will be partially degraded or restored to cell surface (Studzian et al., 2015).

In this study, $\gamma \mathrm{T} 3$ inhibited cell viability of both MCF7 and MCF7-MX cells after $72 \mathrm{hr}$ treatment, in a concentration dependent manner (Figure 4). The $\mathrm{IC}_{50}$ value of $\gamma \mathrm{T} 3$ were $22 \mu \mathrm{M}$ on MCF7. The $\mathrm{IC}_{50}$ value obtained is quite close to the previous study reported that $10 \mu \mathrm{M}$ of $\gamma \mathrm{T} 3$ results in a significant inhibition of cell proliferation of same cell lines (Hsieh et al., 2010). However, another study reported the $\mathrm{IC}_{50}$ value of $\gamma \mathrm{T} 3$ as $7.2 \mu \mathrm{M}$ (Ramdas et al., 2011) in MCF7 cells which is three times lower compared to the results obtained. The differences observed could be due to differences in cell density (Riss et al., 2013) or incubation period as the inhibitory effect of $\gamma \mathrm{T} 3$ is also time dependent (Patacsil et al., 2012). To the best of our knowledge, to date there are no studies on the cytotoxicity of $\gamma \mathrm{T} 3$ on MCF7-MX cells. Here, $\gamma \mathrm{T} 3$ has an $\mathrm{IC}_{50}$ value of $43 \mu \mathrm{M}$ in MCF7-MX cells, two-fold greater than in parental MCF7 cells, which raised the possibility that ABCG2 mediated $\gamma \mathrm{T} 3$ efflux.

The addition of Ko143, a promising ABCG2 inhibitor completely reversed ABCG2-mediated export of MX thus leads to increase in accumulation of MX by approximately seven-fold $(7.17 \pm 2.3)$ in MCF7-MX cells (Figure 3c). This result is in agreement to previous findings showing increased ABCG2 substrates accumulation upon Ko143 administration (Özvegy-Laczka et al., 2005; Wu et al., 2016). The results also demonstrated that ABCG2 overexpressed in MCF7-MX cells are functionally active. As ABCG2 is undetectable in MCF7 cells, administration of Ko143 has no effect on MX accumulation level (Figure 3b). The possibility of $\gamma \mathrm{T} 3$ to be transported via $\mathrm{ABCG} 2$ was then tested with co-administration of known ABCG2 substrate, MX. As no significant difference is observed in MX accumulation in MCF7-MX cells, the data (Figure 3c) suggested that $\gamma \mathrm{T} 3$ does not compete with $\mathrm{MX}$ to be transported via ABCG2 and has no effect in ABCG2mediated $\gamma \mathrm{T} 3$ transportation.

ABCG2 has also been proposed to be involved in cell proliferation as various studies suggested that inhibition of ABCG2 decreased cell proliferation and induced G0/G1 phase arrest in ABCG2 expressing cells (Chen et al., 2010; Liu et al., 2014; Zhang et al., 2016), which also would provide a possible explanation for the difference in $\mathrm{IC}_{50}$ values during a long-term incubation period.

The $\gamma \mathrm{T} 3$ is always co-administered with other compounds, such as statins (Wali and Sylvester, 2007; Wali et al., 2009; Sylvester, 2012) and celecoxib (Shirode and Sylvester, 2010; Shirode and Sylvester, 2011) resulting in synergistic anti-proliferative effects on mammary tumour cell growth. As anti-cancer drugs are often substrates of the $\mathrm{ABC}$ transporters that are found to be overexpressed in various cancer cell lines, understanding the interaction between $\gamma \mathrm{T} 3$ and $A B C$ transporters is essential. Previous studies reported that $\gamma \mathrm{T} 3$ upregulated $\mathrm{ABCB} 1$ expression in human intestinal epithelial cell line (LS180) and this has raised the concern on potential effects of fooddrug interaction especially during drug treatment (Zhou et al., 2004; Abuznait et al., 2011). Study also showed that $\gamma \mathrm{T} 3$ has inhibitory effects on HMGCoA reductase and reversed the MDR in MCF7/Adr cells. Unlike atorvastatin, the effect of $\gamma \mathrm{T} 3$ inhibition was not solely mediated by mevalonate pathway. In fact, $\gamma \mathrm{T} 3$ inhibited the ABCB1 expression, increased the accumulation of doxorubicin in cells, led to enhanced G2/M arrest and cell apoptosis (Ding et al., 2017). Collectively, these studies showed that $\gamma \mathrm{T} 3$ affects $\mathrm{ABCB} 1$ expression and are able to reverse the MDR effect to ABCG2. However, in our study, unlike in $\mathrm{ABCB} 1$ transporter, $\gamma \mathrm{T} 3$ did not reverse the MDR effect of ABCG2 as the MX level showed no significant difference when co-administered with various concentrations of $\gamma \mathrm{T} 3$. This showed that $\gamma \mathrm{T} 3$ functions differently in ABCB1 and ABCG2 transporter although both transporters are from the same family.

In summary, our results indicate that $\gamma \mathrm{T} 3$ is not competing with MX to be transported via ABCG2. However, the assay in this study is limited to determine compounds that are competitive with MX for ABCG2, thus ABCG2 might still have a potential role in the transportation of $\gamma \mathrm{T} 3$. As $\gamma \mathrm{T} 3$ was also found to reduce cell proliferation in ABCG2 expressing cancer cells, therefore more studies need to be done in the future to investigate the interaction of $\gamma \mathrm{T} 3$ with ABCG2 protein to overcome its low bioavailability and to increase the utilisation of this biological compound in cancer therapy. 
(a)

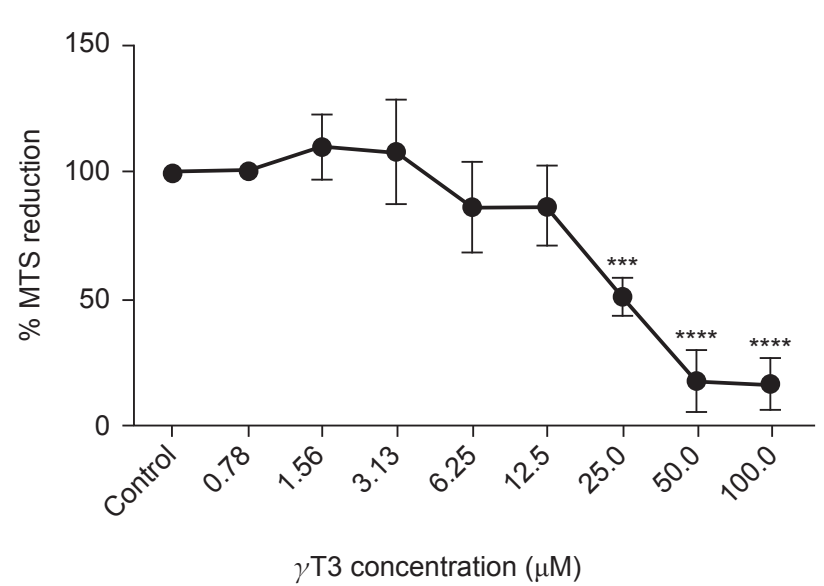

(b)

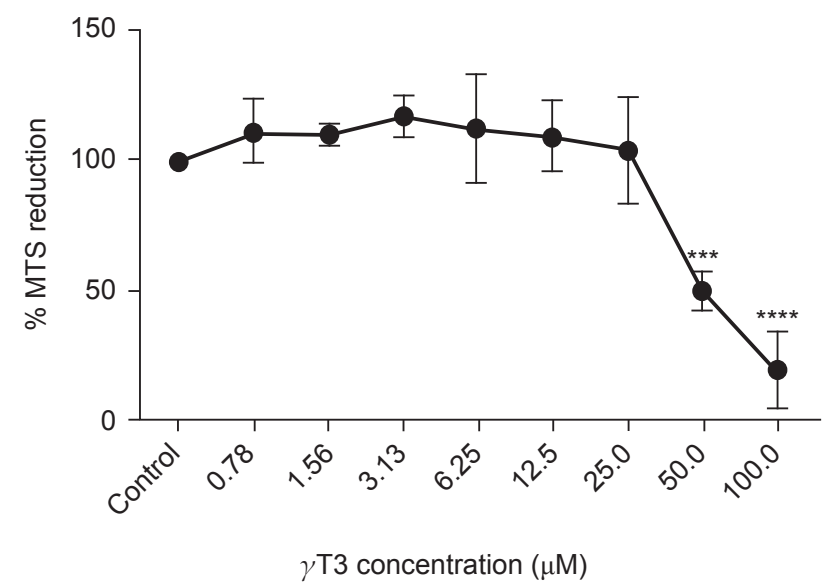

Figure 4. Cytotoxic effect of $\gamma$-tocotrienol ( $\gamma$ T3) on (a) MCF7 (Michigan Cancer Foundation-7) cells and (b) MCF7-MX (mitoxantrone) cells as assessed by MTS assay. The $\gamma T 3$ was shown to be toxic to MCF7 and MCF7-MX cells at $\geq 25 \mu M$ and $\geq 50 \mu M$, respectively. The cell viability was reduced by $50 \%$ at $25 \mu \mathrm{M}(50.73 \% \pm 7)$ and $50 \mu \mathrm{M}(49.35 \% \pm 6.8)$, respectively for MCF7 and MCF7-MX cells. Non-linear regression was not shown due to the level of uncertainty of fitting showed. Data presented as mean $\pm S D, n=3$ (each with six internalised repeats ${ }^{* * *} p<0.001,{ }^{* * * *} p<0.0001$ compared to control as indicated by one-way analysis of variance (ANOVA) followed by Dunnett post-hoc test.

\section{ACKNOWLEDGEMENT}

This research was supported by the Ministry of Higher Education Grant (FRGS/1/2014/SKK01/ UNIM/03/2). We would like to thank Davos Life Science Pte Ltd for providing the $\gamma \mathrm{T} 3$ and Megan Cox and Aaron Horsey for technical assistance.

\section{REFERENCES}

Abuznait, A H; Qosa, H; O'Connell, N D; AkbarianTefaghi, J; Sylvester, P W; El Sayed, K A and Kaddoumi, A (2011). Induction of expression and functional activity of P-glycoprotein efflux transporter by bioactive plant natural products. Food Chem. Toxicol., 49(11): 2765-2772.

Aggarwal, B B; Sundaram, C; Prasad, S and Kannappan, R (2010). Tocotrienols, the vitamin E of the $21^{\text {st }}$ century: Its potential against cancer and other chronic diseases. Biochem. Pharmacol., 80(11): 1613-1631.

Ahsan, H; Ahad, A; Iqbal, J and Siddiqui, W A(2014). Pharmacological potential of tocotrienols: A review. Nutr. Metab. (Lond), 11(1): 52.

Austin Doyle, L and Ross, D D (2003). Multidrug resistance mediated by the breast cancer resistance protein BCRP (ABCG2). Oncogene, 22(47): 7340-7358.

Benderra, Z; Faussat, A M; Sayada, L; Perrot, J Y; Chaoui, D; Marie, J P and Legrand, O (2004). Breast cancer resistance protein and P-glycoprotein in 149 adult acute myeloid leukemias. Clin. Cancer Res., 10(23): 7896-7902.

Chen, Z; Liu, F; Ren, Q; Zhao, Q; Ren, H; Lu, S; Zhang, L and Han, Z (2010). Suppression of ABCG2 inhibits cancer cell proliferation. Int. J. Cancer, 126(4): 841-851.

Ding, Y; Peng, Y; Deng, L; Fan, J and Huang, B (2017). Gamma-tocotrienol reverses multidrug resistance of breast cancer cells with a mechanism distinct from that of atorvastatin. J. Steroid Biochem. Mol. Biol., 167: 67-77.

Doyle, L A; Yang, W; Abruzzo, L V; Krogmann, T; Gao, Y; Rishi, A K and Ross, D D (1998). A multidrug resistance transporter from human MCF-7 breast cancer cells. Proc. Natl. Acad. Sci. USA, 95(26): 15665-15670.

Haider, A J; Briggs, D; Self, T J; Chilvers, H L; Holliday, N D and Kerr, I D (2011). Dimerisation of ABCG2 analysed by bimolecular fluorescence complementation. PLOS ONE, 6(10): e25818.

Haider, A J; Cox, M H; Jones, N; Goode, A J; Bridge, K S; Wong, K; Briggs, D and Kerr, I D (2015). Identification of residues in ABCG2 affecting protein trafficking and drug transport, using coevolutionary analysis of ABCG sequences. Biosci. Rep., 35(4): e00241.

Horsey, A J; Cox, M H; Sarwat, S and Kerr, I D (2016). The multidrug transporter ABCG2: Still more 
questions than answers. Biochem. Soc. Trans., 44(3): 824-830.

Hsieh, T C; Elangovan, S and Wu, J M (2010). Differential suppression of proliferation in MCF7 and MDA-MB-231 breast cancer cells exposed to alpha-, gamma- and delta-tocotrienols is accompanied by altered expression of oxidative stress modulatory enzymes. Anticancer Research, 30(10): 4169-4176.

Imai, Y; Asada, S; Tsukahara, S; Ishikawa, E; Tsuruo, T and Sugimoto, Y (2003). Breast cancer resistance protein exports sulfated estrogens but not free estrogens. Molecular Pharmacology, 64(3): 610-618.

Islam, M O; Kanemura, Y; Tajria, J; Mori, H; Kobayashi, S; Hara, M; Yamasaki, M; Okano, H and Miyake, J (2005). Functional expression of ABCG2 transporter in human neural stem/progenitor cells. Neuroscience Research, 52(1): 75-82.

Kannappan, R; Ravindran, J; Prasad, S; Sung, B; Yadav, V R; Reuter, S; Chaturvedi, M M and Aggarwal, B B (2010). Gamma-tocotrienol promotes TRAIL-induced apoptosis through reactive oxygen species/extracellular signalregulated kinase/p53-mediated upregulation of death receptors. Mol. Cancer Ther., 9(8): 2196-2207.

Kiyose, C; Saito, H; Kaneko, K; Hamamura, K; Tomioka, M; Ueda, T and Igarashi, O (2001). Alpha-tocopherol affects the urinary and biliary excretion of 2,7,8-trimethyl-2 (2'-carboxyethyl)-6hydroxychroman, gamma-tocopherol metabolite, in rats. Lipids, 36(5): 467-472.

Landes, N; Pfluger, P; Kluth, D; Birringer, M; Rühl, R; Böl, G F; Glatt, H and Brigelius-Flohé, R (2003). Vitamin Eactivates gene expression via the pregnane X receptor. Biochemical Pharmacology, 65(2): 269-273.

Liu, H B; Meng, Q H; Du, D W; Sun, J F; Wang, J $B$ and Han, H (2014). The effects of ABCG2 on the viability, proliferation and paracrine actions of kidney side population cells under oxygen-glucose deprivation. Int. J. Medical Sciences, 11(10): 10011008.

Lowry, O H; Rosebrough, N J; Farr, A L and Randall, R J (1951). Protein measurement with the Folin phenol reagent. J. Biological Chemistry, 193(1): 265275.

Miyake, K; Mickley, L; Litman, T; Zhan, Z; Robey, R; Cristensen, B; Brangi, M; Greenberger, L; Dean, M; Fojo, T and Bates, S E (1999). Molecular cloning of cDNAs which are highly overexpressed in mitoxantrone-resistant cells: Demonstration of homology to $\mathrm{ABC}$ transport genes. Cancer Res., 59(1): 8-13.

Mo, W and Zhang, J T (2012). Human ABCG2: Structure, function, and its role in multidrug resistance. Int. J. Biochem. Mol. Biol., 3(1): 1-27.

Nakagawa, M; Schneider, E; Dixon, K H; Horton, J; Kelley, K; Morrow, C and Cowan, K H (1992). Reduced intracellular drug accumulation in the absence of P-glycoprotein (mdr1) overexpression in mitoxantrone-resistant human MCF-7 breast cancer cells. Cancer Research, 52(22): 6175-6181.

Nakanishi, T and Ross, D D (2012). Breast cancer resistance protein (BCRP/ABCG2): Its role in multidrug resistance and regulation of its gene expression. Chin. J. Cancer, 31(2): 73-99.

Özvegy-Laczka, C; Várady, G; Köblös, G; Ujhelly, O; Cervenak, J; Schuetz, J D; Sorrentino, B P; Koomen, G; Váradi, A; Német, K and Sarkadi, B (2005). Function-dependent conformational changes of the ABCG2 multidrug transporter modify its interaction with a monoclonal antibody on the cell surface. J. Biological Chemistry, 280(6): 4219-4227.

Patacsil, D; Tran, A T; Cho, Y S; Suy, S; Saenz, F; Malyukova, I; Ressom, H; Collins, S P; Clarke, R and Kumar, D (2012). Gamma-tocotrienol induced apoptosis is associated with unfolded protein response in human breast cancer cells. J. Nutr. Biochem., 23(1): 93-100.

Pope, S A; Clayton, P T and Muller, D P (2000). A new method for the analysis of urinary vitamin E metabolites and the tentative identification of a novel group of compounds. Arch Biochem Biophys., 381(1): 8-15.

Ramdas, P; Rajihuzzaman, M; Veerasenan, S D; Selvaduray, KR; Nesaretnam, Kand Radhakrishnan, A K (2011). Tocotrienol-treated MCF-7 human breast cancer cells show down-regulation of API5 and up-regulation of MIG6 genes. Cancer Genomics and Proteomics, 8(1): 19-32.

Riss, T L; Moravec, R A; Niles, A L; Duellman, S; Benink, H A; Worzella, T J and Minor, L (2013). Cell viability assays. Assay Guidance Manual [Internet]: 785-796.

Ross, D D; Yang, W; Abruzzo, L V; Dalton, W S; Schneider, E; Lage, H; Dietel, M; Greenberger, L; Cole, S P and Doyle, L A (1999). A typical multidrug resistance: Breast cancer resistance protein messenger RNA expression in mitoxantroneselected cell lines. J. Natl. Cancer Inst., 91(5): 429-433. 
Scharenberg, C W; Harkey, M A and Torok-storb, B (2002). The ABCG2 transporter is an efficient Hoechst 33342 efflux pump and is preferentially expressed by immature human hematopoietic progenitors. Blood, 99(2): 507-512.

Shah, S; Gapor, A and Sylvester, P W (2003). Role of caspase- 8 activation in mediating vitamin E-induced apoptosis in murine mammary cancer cells. Nutr. Cancer, 45(2): 236-246.

Shirode, A B and Sylvester, P W (2011). Mechanisms mediating the synergistic anticancer effects of combined gamma-tocotrienol and celecoxib treatment. J. Bioanalysis and Biomedicine, 3: 1-7.

Shirode, A B and Sylvester, P W (2010). Synergistic anticancer effects of combined $\gamma$-tocotrienol and celecoxib treatment are associated with suppression in Akt and NFkB signaling. Biomedicine and Pharmacotherapy, 64(5): 327-332.

Stacy, A E; Jansson, P J and Richardson, D R (2013). Molecular pharmacology of ABCG2 and its role in chemoresistance. Mol. Pharmacol., 84(5): 655-669.

Studzian, M; Bartosz, G and Pulaski, L (2015). Endocytosis of ABCG2 drug transporter caused by binding of 5D3 antibody: Trafficking mechanisms and intracellular fate. Biochimica et Biophysica Acta Molecular Cell Research, 1853(8): 1759-1771.

Suzuki, M; Suzuki, H; Sugimoto, Y and Sugiyama, $Y$ (2003). ABCG2 transports sulfated conjugates of steroids and xenobiotics. J. Biological Chemistry, 278(25): 22644-22649.

Sylvester, P W (2012). Synergistic anticancer effects of combined $\gamma$-tocotrienol with statin or receptor tyrosine kinase inhibitor treatment. Genes Nutr., 7(1): 63-74.
Sylvester, P W; Shah, S J and Samant, G V (2005). Intracellular signaling mechanisms mediating the antiproliferative and apoptotic effects of gammatocotrienol in neoplastic mammary epithelial cells. J. Plant Physiol., 162(7): 803-810.

Uggla, B; Ståhl, E; Wågsäter, D; Paul, C; Karlsson, M G; Sirsjö, A and Tidefelt, U (2005). BCRP mRNA expression v. clinical outcome in 40 adult AML patients. Leuk. Res., 29(2): 141-146.

Wali, V B; Bachawal, S V and Sylvester, P W (2009). Combined treatment of gamma-tocotrienol with statins induce mammary tumor cell cycle arrest in G1. Exp. Biol. Med. (Maywood), 234(6): 639-650.

Wali, V B and Sylvester, P W (2007). Synergistic antiproliferative effects of gamma-tocotrienol and statin treatment on mammary tumor cells. Lipids, 42(12): 1113-1123.

Wu, C P; Hsieh, Y J; Hsiao, S H; Su, C Y; Li, Y Q; Huang, Y H; Huang, C W; Hsieh, C H; Yu, J S and Wu, Y S (2016). Human ATP-binding cassette transporter ABCG2 confers resistance to CUDC907, a dual inhibitor of histone deacetylase and phosphatidylinositol 3-kinase. Molecular Pharmaceutics, 13(3): 784-794.

Zhang, W; Chen, J; Ding Q and Liu, J (2016). Upregulation of ABCG2 promotes cell proliferation in renal cell carcinoma and associate with clinicopathologic features. Int. J. Clin. Exp. Pathol., 9(7): 7123-7131.

Zhou, C; Tabb, M M; Sadatrafiei, A; Grün, F and Blumberg, B (2004). Tocotrienols activate the steroid and xenobiotic receptor, SXR, and selectively regulate expression of its target genes. Drug. Metab. Dispos., 32(10): 1075-1082. 